\title{
Perceptions and Opinions of the Usability of Simulations in a Mathematics Methods Course for Elementary Pre-Service Teachers
}

\author{
Jair J. Aguilar \\ College of Education and P-16 Integration, The University of Texas Rio Grande Valley \\ 1201 W University Dr, Edinburg, Texas 78539, USA \\ E-mail: jair.aguilar@utrgv.edu \\ James A. Telese \\ College of Education and P-16 Integration, The University of Texas Rio Grande Valley \\ One W. University Blvd, Brownsville, Texas 78520, USA \\ E-mail: james.telese@utrgv.edu
}

\begin{abstract}
The acceptance, implementation, and adoption of emerging technologies in teacher preparation programs has significantly evolved, and it is now seen as a tool that enhances teacher's teaching skills particularly during the first years of the program. The use of new technologies like Mixed-Reality Simulations (MRSs) in the preparation of future teachers, provides them the opportunity of developing teaching skills in a safe environment. In this article, the researchers studied the perceptions and opinions of Elementary Pre-Service Mathematics Teachers (EPSMT) that were exposed to the use MRSs in a mathematics methods course. The research questions were: (1) What are the EPSMTs s' perceptions toward the use of MRSs as part of their teacher preparation program? and (2) what are the opinions of the EPSMTs in regard to the benefits and usefulness of MRS to leverage their teaching skill in productive mathematical talk moves? Results of the study shows that EPSMTs perceive the use of MRSs as beneficial tool that effectively simulate classroom environments and students' behaviors. The above is relevant since it facilitates the integration and adoption of state-of-the-art technologies like MRSs.
\end{abstract}

Keywords: Pre-service Teachers, Mixed-Reality Simulations, Perceptions, Opinions.

DOI: $10.7176 / \mathrm{JEP} / 11-12-02$

Publication date: April $30^{\text {th }} 2020$

\section{Introduction}

The acceptance and perceptions of a technology is relevant and pertinent because it would facilitate its adoption and integration (Jurison, 2000). In this regard, the integration of new technologies in education, and especially in teacher preparation programs, offer future teachers a variety of opportunities to be better prepared. Pre-service teacher's perceptions, views, and opinions on how technology can help them acquire new knowledge and teaching skills, can be influenced if technologies are integrated, presented, and linked to the goals and objectives of the courses in a preparation program (Gordon, Brayshaw, \& Grey, 2015; Russell, Bebell, O'Dwyer \& O'Connor, 2003). For example, state of the art technologies like Mixed-Reality Simulations (MRSs), can be integrated in methods courses to enhance pre-service teachers' abilities related to the implementation of high-leverage practices [HLP] (Ball, \& Forzani, 2011). MRSs software like TLE TeachLiveTM/MursionTM (Andreasen \& Haciomeroglu, 2009) are instructional-educational tools intended to provide pre-service teachers early simulated experiences that would enhance and strengthen their teaching skills in a safe environment (Hixon \& So, 2009). The goal of this article is to present results of a study where elementary pre-service mathematics teachers (EPSMT) were exposed to the use of MRSs during a mathematics methods course. The use of MRSs with the EPSMTs have the intention of fostering HLPs use of productive mathematical talk moves [PMTMs] (Chapin, O'Connor, \& Anderson, 2009; Moyer \& Milewicz, 2002; Ginsburg, 1997), such as eliciting, assessing, and questioning elementary students while solving mathematical tasks. The purpose of this study was to examine elementary preservice mathematics teachers' perceptions of the usefulness of MRs in their role to foster productive mathematics talk. To this end, the researchers addressed the following questions: (1) What are the EPSMTs s' perceptions toward the use of MRSs as part of their teacher preparation program? and (2) what are the opinions of the EPSMTs in regard to the benefits and usefulness of MRS to leverage their teaching skill in productive mathematical talk moves? EPSMTs' responses were captured through an instrument used for this purpose. The EPSMTs not only enjoyed the use of MRSs as part of the math methods course, but that they perceived MRSs as a tool that helped them to boost their teaching skills in eliciting the student's thoughts and promoting discourse through questioning.

\section{Theoretical Framework and Perspectives}

The acceptance, implementation, and adoption of emerging technologies in teachers' preparation programs has 
significantly evolved (Birkollu, Yucesoy, Baglama, \& Kanbul, 2017), and it is now seen as a tool that enhances teacher's teaching skills (Rakhimova, 2016). Actually, the integration of technologies in the teaching-learningpreparation process of pre-service teachers is now as important as the content and pedagogy knowledge (Stobaugh \& Tassell, 2011). Comparable to how technologies are incorporated in schools to increase the student's learning acquisition, teachers' preparation programs must engage and expose pre-service teachers to technologies that enhance their experience, develop their skills, and potentialize their knowledge acquisition (Dieker, Rodriguez, Lignugaris/Kraft, Hynes, \& Hughes. 2014; Niess, 2005).

\subsection{Perceptions and opinions about technologies}

Pre-service teachers acknowledge that technologies are important, however, this does not fully reflect an understanding of its benefits (Kelly-McHale, 2013). In addition, variables related to self-efficacy, belief, and culture can affect how technology is perceived (Nishino, 2012). For pre-service teachers to really acquire the theoretical understandings of the benefits of being exposed to the technologies (e.g. MRSs), their perspectives and opinions in regard to the usefulness must be shaped in to what Venkatesh, Morris, Davis, \& Davis (2003) has called the theory of acceptance and perception of the use and exposure of technology.

In this paper, perceptions and opinions are studied considering the lens used by Venkatesh et al. According to Venkatesh et al., pre-service teachers' perceptions of the benefits and usefulness of the use a of technology can be significantly enhanced, when it is well addressed in preparation programs. Venkatesh et al. adopted the definition of usefulness (Davis, 1989) as the measure for which an individual believes or perceive that the use of a particular technology (e.g., MRSs) enhances the work that is performed, in which case-for the EPSMTs and the purpose of this study - would be the learning process and teaching skills (i.e., PMTMs) in problem solving to elicit student's thoughts. Then, on one hand, in this study perception is conceived as the way pre-service teachers think about how useful mixed-reality simulation is in their teacher preparation program. On the other hand, opinions are considered to be the pre-service teachers' views and judgments about the technology. For example, a pre-service teacher may think (i.e., perception) that the use of MRS is beneficial as an educational-technological learning tool, but might not like it (i.e., opinion) because it could potentially expose areas of weakness. In this sense, the perceptions and opinions of the EPSMTs matters because it will determine the level of commitment and openness to learn and develop their teaching skills, which in return will show the level of success of implementing MRSs.

\subsection{Mixed-Reality Simulations as instructional tool}

Teachers and pre-service teachers are mostly familiar with common applications and software (Shoffner, 2009), but they have not had much experience with integrated emerging technologies like Mixed-Reality Simulations, in which the participants (i.e., elementary pre-service mathematics teachers) have "repeated trials involving high stakes situations without risking the loss of valuable resources" (Dieker et al., 2014, p.22). Mixed-Reality Simulations are software that promote experiential learning (Kolb, 2014) for pre-service teachers, and where they are at the center of a constructivist teaching-learning process (Hirumi, 2002). During an MRS session, simulated students called avatars are depicted in a virtual classroom that provides pre-service teachers the opportunity of experiencing teaching-related practices in a safe simulated environment, particularly — but not limited — during the first years of the teachers' preparation program in which in many instances pre-service teachers have few teaching opportunities. The avatars are controlled by a trained educational specialist. Then, for what it seems, in the eye of the pre-service teacher, and interaction with a computer animated avatar, is in reality an interaction with another person. MRSs are not intended to replace the real-life experience of pre-service teachers with real students, but rather to help them be ready and better prepared for their teaching responsibilities. According to Dieker, Rodriguez, Lignugaris/Kraft, Hynes, \& Hughes (2014), MRSs have the potential of "improving [and affect] teacher education" (p. 24) by supporting the learning and use of technologies, and by offering a safe environment where to rehearse likely real experiences. MRSs is described as a tool that can provide pre-service teachers opportunities to practice various instructional strategies in a variety of environments, develop skills in providing feedback, integrate technology, and practice teaching content-related concepts (Hixon \& So, 2009). MRSs then serves as a technological tool that is intended for pre-service teachers to develop high leverage practices skills (Cohen, 2015) such as how to assess and elicit their students' thoughts (Hatton, Birchfield, \& MegowanRomanowicz, 2008). In addition, MRS promotes critical, reflective, and evaluative thinking by encouraging preservice teachers to respond and make decisions to the open-ended situations that emerged during an MRS session. One important aspect of simulated environments is that they provide the pre-service teacher —or participant—a sense of reality in which there is a "real presence", which is defined by Dieker et al., as the perception that something real is happening

\section{Methodology}

The results presented in this article are part of an ongoing larger study in which MRSs technologies are used to 
foster high leverage practices (Ball \& Forzani, 2011) with EPSMT's. This larger study was designed to examine the EPSMT's productive mathematical talk moves when conducting a clinical interview. The report here depicts the perceptions, views, and opinions that EPSMTs have when they are exposed to the MRSs. For the purpose of providing the reader with an overview of the full study, in the following paragraph the researchers detail the setting in which the EPSMTs were instructed with the use of MRSs.

\subsection{Data Collection and Participants}

Participants were one hundred sixty-six $(N=166)$ elementary pre-service mathematics teachers taking a mathematics methods course from the Fall 2018 to Fall 2019 from which 92\% were females and 8\% males. All participants were in their first year of the teaching preparation program at a minority serving institution. The EPSMTs were required - as part of the course assignment - to conduct a clinical interview with an - realelementary student to assess and elicit the students' understanding when solving a mathematical task. To this end, the EPSMTs were exposed to in class rehearsals, readings, videos, and lectures, and asked to participate in three MRSs sessions through the semester. Each MRS session lasted between 7 and 12 minutes and was video-recorded. In every session the EPSMTs were required to implement a three different mathematical tasks, which were given to them by the instructor. The mathematical activities followed the cognitively guided instruction framework of Carpenter, Fennema, Franke, Levi, \& Empson, (2014). The MRSs sessions were distributed through the semester with one month apart to ensure the EPSMTs assimilated the theoretical and pedagogical concepts discussed in class. Subsequently, after each MRS session the EPSMTs were required to submit a one-page self-reflection and provide a peer-feedback constructive-critic of the MRSs videos within their small working-teams. The teams were randomly formed with three to four members, and their feedbacks were asked to be submitted though an online platform used for this purpose. After the EPSMTs conducted their clinical interview, they were required to submit the audios, transcripts, and artifacts of the interview. Lastly, the EPSMTs were asked to answer a questionnairewhich is the main focus of this report-about their perceptions, views, and opinions toward the used of MRSs as part of their teaching-training, and as a way to gain knowledge and experience in eliciting a student's thoughts through the use of PMTMs.

\subsection{Instrument}

The instrument used to measure the EPSMTs perceptions, views, and opinions was adapted from Hudson, Voytecki, \& Zhang, (2018), Bousfield, (2017), and Rasimah, Ahmad, \& Zaman, (2011), and tailored to meet the purpose and needs of this study. It comprises 27 questions in a 5-Likert-scale type ranging from strongly agree to strongly disagree (see Appendix A). Also, four additional open-ended questions were included to capture the EPSMTs opinions about what they liked or disliked most, challenges rehearsing with MRS, and perceptions of the benefits of being exposed to MRSs.

\section{Findings and discussion}

During the first year of teaching preparation programs, many EPSMTs are rarely exposed to well-structured, engaged teaching experiences (Freeman, 2010), instead, they are only required to conduct field-observation hours, mainly because of the complexity of the logistic, resources, and efforts that such task required. Therefore, it is during this time that MRSs serves an alternative educational tool. In this section, the researchers present the results of the study and answer the question stated before. Also, examples of EPSMTs' opinion are presented as way to highlight their views.

\subsection{Perceptions that something real is happening}

The implementation of MRSs, allows EPSMTs to engage in simulated classrooms settings that simulates real classrooms environments and students (i.e., the avatars). In this regard, 94 percent of the EPSMTs agree or strongly agree that MRSs sessions seemed like a real classroom experience, and 97 percent expressed that rehearsing with the MRSs is a positive experience to develop teaching skills. For example, some EPSMTs opinions portrait the views of the integration of MRSs as part of their preparation: "It provided unexpected experiences that I had to work around, which I felt prepared me for the real world"; "How the avatars speak and act like actual children especially with their responses"; "I liked that I was able to practice as if it was a real classroom"; "I was able to practice like if I actually was in front of the class with real students". These EPSMTs' opinions about how the MRS provide an experience that simulate a real-life situation, allows for an easier integrations and adoption of the technology, and helped them to engage in the learning and developing-of-skill process that was planned for them.

The use of MRSs in a teacher preparation program - as mentioned before - is not intended to displace the real-experience, but rather to enhance the EPSMTs' preparation experience (Peterson-Ahmad, 2018), in a safe environment (Hatton, Birchfield, \& Megowan-Romanowicz, 2008). The EPSMTs in the study acknowledged the above, for which 97 percent agree or strongly agree that using MRSs is an effective way to practice new classroom skills, particularly in mathematics for which 94 and 97 percent respectively, expressed that they feel more 
confident to effectively teach mathematics, or prepare to engage their students in a lessons that involve discourse about problem-solving activities with the use of productive mathematical talk moves. For instance, one EPSMTs highlighted the above; "What I liked about the Mixed-Reality Simulation is that I was able to practice math word problems like if I would actually be teaching it to real students".

\subsection{Mixed-Reality Simulation for teaching}

As mentioned in the methods section, the EPSMTs were exposed to several different instructional strategies (e.g., lectures, videos, rehearsals, readings and discussions), and a set of 3 MRSs sessions. All these helped the EPSMTs acquire the teaching skills they need for their future responsibilities and being ready for one of the major assignments in the course: The clinical interview with a real elementary student. In this regard, 88 percent of the EPSMTs agree or strongly agree that after been exposed to the MRSs they felt prepared to conduct a clinical interview to assess, question, and elicit their students' thoughts and understanding using PMTMs. These was also recognized by another EPSMTs: "It was fun and engaging... the simulations helped to solidify topics taught in class, particularly teacher-talk skills [i.e., PMTMs]". Similarly, 94 percent of the EPSMTs agree or strongly agree that their interaction with the MRSs helped them to create a plan for the clinical interview, increasing and improving their experience, as expressed by an EPSMTS: "[the experience]...was beneficial because it taught me that students will have different methods of solving and some might need more assistance, so you always have to be prepared".

\subsection{Recognition of the Benefits of Mixed-Reality Simulations}

In the end, the EPSMTs recognized the benefit of been exposed to a state-of-the-art technology that serve as a tool to improve, increase, and enhance the acquisition of high-leverage practices, as mentioned by one EPSMTs: "[the MRSs experience] gave me practice before going out and teaching real students". In fact, 97 percent of the EPSMTs agree or strongly agree with the above, and 94 percent of them would like to continue using MRSs in other courses as part of their teaching preparation program. In fact, one of the comments many EPSMTs made was that they wished they could have the opportunity of having more time interacting in MRSs.

\section{Conclusions}

How teachers are prepared is extremely relevant, since it's during this time when they acquire the skills and knowledge for their future endeavor. Then, it is relevant to report findings of this study, so others teacher preparation programs learn about the benefits and potential of integrating MRSs within their courses, and enhance their student's teaching skills from the first day of the preparation program. As depicted above, the EPSMTs held positive perceptions and opinions about the usefulness of MRSs, which facilitated its integration.

The use of MRSs in a teacher preparation program, particularly in a math-method course, is an innovative way to enhance the EPSMTs' acquisition of teaching skills, and although a larger sample is needed-which represents a limitation - the EPSMTs that participated in this study showed that they perceived MRSs as a useful tool, that helped them to improve their teaching skills - particularly in regard to eliciting and questioning students in a clinical setting or classroom discourse - and that they would like to use it in other courses during their preparation program. The well guided and planned use of technology (Venkatesh et al., 2003) — as MRSs are implemented here-helped the EPSMTs perceive the MRSs as a tool intended to enhance their HLPs (Ball \& Forzani, 2011) skills, and not to substitute the real experience, which is a common limitation for first year's preservice teachers.

The preliminary results presented here are only the first phase of an ongoing larger study that involve the analysis of the EPSMTs' transcripts once they have conducted a clinical interview with a real elementary student. The study and analysis of the transcripts will reveal the extent to which the EPSMTs used productive mathematical talk moves for eliciting their students' thoughts and ideas, and as way to prove the effectiveness of MRSs as a teaching strategy tool in a teacher preparation program. The results of this study will be linked to the one presented here and will be reported in another manuscript. Meanwhile, more data are continuing to be collected regarding the EPSMTs' perceptions, views and opinions on the use of MRSs as part of their teacher preparation, which is intended to be analyzed and reported in a near future.

Finally, the implementation of Mixed-Reality Simulations is still relatively new, and more research is needed to inform the field. In particular, more research is needed that examine the effectiveness of MRS to implement these HLP skills in actual classroom settings. Also, research is needed to study the extent in which pre-service elementary teachers reflect on their teaching practices and the quality of feedback provided to students.

\section{References}

Andreasen, J. B., \& Haciomeroglu, E. S. (2009). Teacher training in virtual environments. In annual meeting of the North American Chapter of the International Group for the Psychology of Mathematics Education, Atlanta, GA. 
Ball, D. L., \& Forzani, F. M. (2011). Building a Common Core for Learning to Teach: And Connecting Professional Learning to Practice. American Educator, 35(2), 17-31.

Birkollu, S. S., Yucesoy, Y., Baglama, B., \& Kanbul, S. (2017). Investigating the attitudes of pre-service teachers towards technology based on various variables. TEM Journal, 6(3), 578-583.

Bousfield, T. (2017). An Examination of Novice and Expert Teachers' Pedagogy in a Mixed-Reality Simulated Inclusive Secondary Classroom Including a Student Avatar with Autism Spectrum Disorders. Dissertation.

Carpenter, T., Fennema, E., Franke, M. L., Levi, L., \& Empson, S. B. (2014). Children's Mathematics, Second Edition: Cognitively Guided Instruction. Heinemann; 2nd edition.

Chapin, S. H., O'Connor, C., O'Connor, M. C., \& Anderson, N. C. (2009). Classroom discussions: Using math talk to help students learn, Grades K-6. Math Solutions.

Cohen, J. (2015). Challenges in identifying high-leverage practices. Teachers College Record, 117(7). 1-41.

Davis, F. D., Bagozzi, R. P., \& Warshaw, P. R. (1989). User acceptance of computer technology: a comparison of two theoretical models. Management science, 35(8), 982-1003.

Dieker, L. A., Rodriguez, J. A., Lignugaris/Kraft, B., Hynes, M. C., \& Hughes, C. E. (2014). The potential of simulated environments in teacher education: Current and future possibilities. Teacher Education and Special Education, 37(1), 21-33.

Freeman, G. G. (2010). Strategies for Successful Early Field Experiences in a Teacher Education Program. Srate Journal, 19(1), 15-21.

Ginsburg, H. (1997). Entering the child's mind: The clinical interview in psychological research and practice. Cambridge University Press.

Gordon, N., Brayshaw, M., \& Grey, S., (2015). Motivating and Engaging Students Through Technology. In Hawkins (Ed), Student Engagement: Leadership Practices, Perspectives and Impact of Technology (78-89), Hauppauge, NY: Nova Science Publishers.

Hatton, S., Birchfield, D., \& Megowan-Romanowicz, M. C. (2008). Learning metaphor through mixed-reality game design and game play. Proceedings of the 2008 ACM SIGGRAPH symposium on Video games. 67-74.

Hénard, F., \& Roseveare, D. (2012). Fostering quality teaching in higher education: Policies and Practices. An IMHE Guide for Higher Education Institutions, 7-11.

Hixon, E., \& So, H. J. (2009). Technology's role in field experiences for preservice teacher training. Journal of Educational Technology \& Society, 12(4), 294-304.

Hudson, M. E., Voytecki, K. S., \& Zhang, G. (2018). Mixed-Reality Teaching Experiences Improve Preservice Special Education Students' Perceptions of their Ability to Manage a Classroom. Journal for Virtual Worlds Research, 11(2), 1-16.

Jurison, J. (2000). Perceived value and technology adoption across four end user groups. Journal of Organizational and End User Computing (JOEUC), 12(4), 21-28.

Kelly-McHale, J. (2013). The influence of music teacher beliefs and practices on the expression of musical identity in an elementary general music classroom. Journal of Research in Music Education, 61(2), 195- 216.

Kolb, D. A. (2014). Experiential learning: Experience as the source of learning and development. FT press.

Kunnen, E. (2015). Emerging technologies to enhance teaching and enable active learning. Educause Review. Retrieved February, 3, 2019 from https:/er.educause.edu/articles/2015/8/emerging-technologies-to-enhanceteaching-and-enable-active-learning.

Moyer, P. S., \& Milewicz, E. (2002). Learning to question: Categories of questioning used by preservice teachers during diagnostic mathematics interviews. Journal of Mathematics Teacher Education, 5(4), 293-315.

Niess, M. L. (2005). Preparing teachers to teach science and mathematics with technology: Developing a technology pedagogical content knowledge. Teaching and Teacher Education, 21, 509-523.

Nishino, T. (2012). Modeling teacher beliefs and practices in context: A multimethods approach. The Modern Language Journal, 96(3), 380-399. http://dx.doi.org/10.1111/j.1540-4781.2012.01364.x

Ottenbreit-Leftwich, A. T., Glazewski, K. D., Newby, T. J., \& Ertmer, P. A. (2010). Teacher value beliefs associated with using technology: Addressing professional and student needs. Computers \& education, 55(3), $1321-1335$.

Peterson-Ahmad, M. (2018). Enhancing Pre-Service Special Educator Preparation through Combined Use of Virtual Simulation and Instructional Coaching. Education Sciences, 8(1), 10-19.

Popham, W. J. (2001). Teaching to the Test?. Educational leadership, 58(6), 16-21.

Rakhimova, R. (2016). How technology enhances teaching and learning. Теория и практика современной науки, (11), 662-664.

Rasimah, C. M. Y., Ahmad, A. \& Zaman, H. B. (2011). Evaluation of user acceptance of mixed reality technology. In Hong, K. S. \& Lai, K. W. (Eds), ICT for accessible, effective and efficient higher education: Experiences of Southeast Asia. Australasian Journal of Educational Technology, 27(Special issue, 8), 1369-1387.

Russell, M., Bebell, D., O'Dwyer, L., \& O'Connor, K. (2003). Examining teacher technology use: Implications for preservice and inservice teacher preparation. Journal of teacher Education, 54(4), 297-310. 
Sawchuk, S. (2015). Teacher evaluation: An issue overview. Education Week, 35(3), 1-6

Shoffner, M. (2009). Personal attitudes and technology: Implications for preservice teacher reflective practice. Teacher Education Quarterly, 36(2), 143-161.

Stobaugh, R., \& Tassell, J. (2011). Analyzing the degree of technology use occurring in pre-service teacher education. Educational Assessment, Evaluation and Accountability, 23(2), 143-157.

Venkatesh, V., Morris, M., Davis, G. B., \& Davis, F. D. (2003), User acceptance of Information Technology: Toward a unified view, MIS Quarterly, 27(3), 425-478.

\section{APPENDIX A - Questionnaire}

1. I like to experience with new technologies.

2. I enjoy rehearsing with Mixed-Reality Simulations.

3. I was unhappy when the Mixed-Reality Simulations sessions were over.

4. I would like to repeat the same experience using Mixed-Reality Simulations.

5. I feel that using Mixed-Reality Simulations enhanced my learning experience.

6. I feel better prepared to teach after my Mixed-Reality Simulation session.

7. Using the Mixed-Reality Simulation is an effective way to practice new classroom skills.

8. My Mixed-Reality Simulation session seemed like a real classroom experience.

9. The Mixed-Reality Simulation's students seemed like real elementary students.

10. After practicing my teaching methods using Mixed-Reality Simulations, I am more confident that I can effectively teach mathematics concepts.

11. After the MRS, I feel prepared to conduct a clinical interview to assess and elicit students thoughts and understanding using mathematics productive talk moves.

12. After my Mixed-Reality Simulation sessions, I have more confidence that I can engage students in a discourse about problem-solving activities.

13. I was able to effectively manage the interview during my Mixed-Reality Simulation sessions.

14. After the Mixed-Reality Simulation rehearsal, I feel prepared to orchestrate a group discussion in a classroom to assess understanding using mathematics productive talk moves.

15. After Rehearsing with the Mixed-Reality Simulations, I felt my Clinical interview with an elementary student was conducted effectively.

16. After the Mixed-Reality Simulation sessions, I have more confidence in my ability to manage undesired behaviors in group discussion.

17. After my Mixed-Reality Simulation sessions, I am better prepared to teach lessons involving problem solving.

18. I felt the Mixed-Reality Simulation's interviews were conducted effectively.

19. I felt like I was in a real classroom during the sessions.

20. The Mixed-Reality Simulation sessions prepared me to conduct the clinical interview.

21. The Mixed-Reality Simulation rehearsals helped me to create a plan for the clinical interview with an elementary student.

22. My experience with Mixed-Reality Simulations prepared me to teach.

23. I would like to use Mixed-Reality Simulation to develop my teaching skills in other courses.

24. Reflecting after each Mixed-Reality Simulation helped me to be better prepared for the next rehearsal.

25. Receiving peer feedback after each Mixed-Reality Simulation helped me to reflect on my strengths and weakness in assessing a students' understanding.

26. Receiving peer feedback after each Mixed-Reality Simulation helped me to reflect on my strengths and weakness in conducting a clinical interview.

27. Providing feedback to my peers after each Mixed-Reality Simulation helped me to reflect in my own teaching skills.

\section{Open-Ended questions}

1. What did you like the most about the Mixed-Reality Simulation?

2. What did you dislike the most about Mixed-Reality Simulation?

3. What do you consider was the most challenging aspect of interacting in with Mixed-Reality Simulations?

4. Do you believe using Mixed-Reality Simulation was beneficial for your Teacher-Preparation? If yes, why? if not, why? 